\title{
Development of Alloys on an Iron Basis
}

\author{
Zh. Zhumadilova \\ Kazakh National Technical University named after K.I. Satpayev \\ (Republic of Kazakhstan, Almaty, Satpayev st. 22) \\ E-mail: zhanar85@mail.ru
}

\begin{abstract}
At the industrial enterprises (ferrous metallurgy, machine-building, transport, etc.) the percentage share of noise shock provenance is very high.

In materials technology use various methods of research and the tests, necessary for reception enough full and a solid data about properties of metals and polymers and about their change depending on a chemical compound, structures and processing.

In work results of experiment, new developed damping alloys DAZ-3, DAZ-4, DAZ-5 (DAZdamping alloys by Zhumadilova) are offered. Microstructures and damping properties of multiple alloyed damping alloys are offered.

Thermal processing makes essential impact on damping properties of alloys. Tempering raises damping characteristics that, certainly, is connected with formation martensite structures. Annealing, not leading to grain growth, and resign imperfections of structure reduces dampening.
\end{abstract}

Keywords: metallurgy, chemical and damping properties of alloys, annealing, tempering, a microstructure.

\section{INTRODUCTION}

The steel is especially valuable constructional material to which can give almost any form rolling, punching and pressing, moulding or processing by cutting. Through alloying and heat treatments, it is possible to receive steels with diversified physical and chemical properties. So, for example, steels that are so soft can be processed the simple manual metalwork tool, and others are so firm that allow to cut glass. 
Varying structure, it is possible to receive steels with rather differing properties - alloyed, corrosion-proof, tool. More than all other grades, it is melted a carbonaceous steel. The carbonaceous steel is an alloy of iron with carbon and manganese. As it was already mentioned, manganese is added for suppression of harmful action of oxygen and the sulphur, present at a steel. Carbon defines mechanical properties of a steel. The carbon maintenance in a steel can make from 0.1 to 1 , and $2 \%$. The steel containing $0.1-0.3 \%$ of carbon, is strong enough and plastic enough. Hire of such steel in a kind I-beam a profile is applied as building beams. From thin sheet low carbonaceous steels do bodies of cars and cans.

One of the most important features of a steel consists that its properties can be changed in very wide range simple change of the maintenance of carbon. The more in steels, the more its strength at a stretching, but the plasticity, i.e. deformation before destruction is less than carbon. Not alloyed steel with the average maintenance of carbon is suitable for such products from which durability and resistance to deterioration, for example for rails are required.

For practical application of metals and manufacturing of metal products it was necessary to learn to process metal. It has appeared that if to heat up firm metal at the raised temperature it becomes soft, and at cooling metal again becomes firm. Thus very much the great influence on properties of metals is rendered by heating and cooling conditions. At fast cooling (training), for example, in water, properties of metal sharply improve.

\section{CARRYING OUT OF EXPERIMENT AND RESULTS OF WORK}

\subsection{Influence of the Chemical Compound on Damping Properties of Steels}

By working out of alloys high damper one of the basic criteria is inadmissibility of essential decrease bending strength properties. Therefore one of the reasons of a choice as alloying elements iron carbide alloys of silicon, manganese and nickel was that among the basic alloying elements (most often applied) these elements are stronger than others strengthen ferrite [1].

Skilled alloys melted in the crucible induction furnace capacity $12 \mathrm{~kg}$ with the basic fettling. As an initial material served armko-iron. Alloyed made $97.6 \%$ th metal manganese, $77.5 \%$ th FeSi and 99,98\%th metal nickel. As the carbon maintenance additive synthetic pig-iron with the maintenance of carbon of $3.9 \%$ served. Steels cast in metal mould in the sizes 210x115x115 mm.

In [2] essential influence of technology processing on the general level of sound pressure sheet low carbonaceous steels has been revealed. For the purpose of an exception of influence of technology of processing on damping characteristics investigated steels melt, to a rolling, mechanical processing spent on uniform technology on the same equipment. 
Samples before rolling heated up in the laboratory furnace to temperature $1200^{\circ} \mathrm{C}$ with endurance 1 hour. Ingots rolled on one-felling rolling mill DUO on strips with the final sizes 700x90x10 (12) mm. After each pass of a strip placed in the furnace for temperature achievement $1200^{\circ} \mathrm{C}$. Samples for research of acoustic and physicomechanical properties cut out from rolling strips under the scheme, representation on Fig. 1.

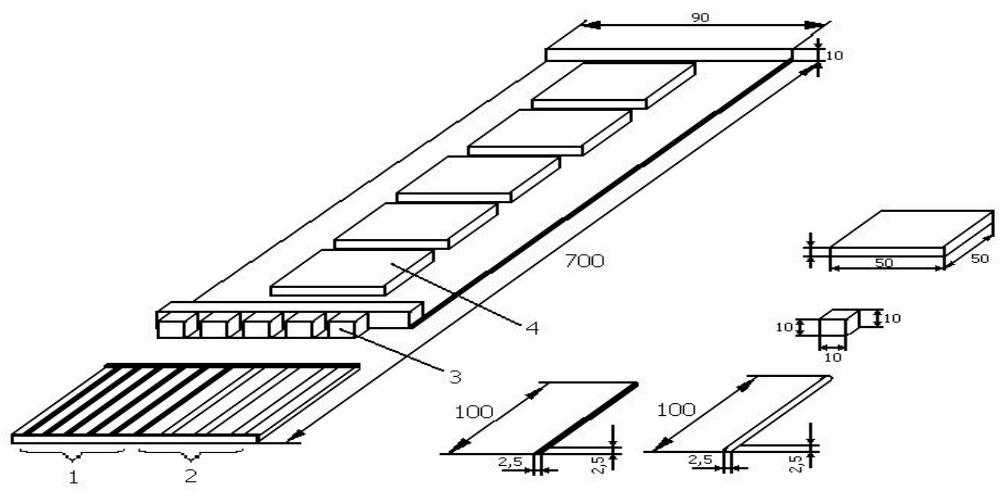

Figure -1 . The scheme of a cutting of samples for research:

1 -internal friction; 2 - specific electro resistance;

3 - metallographic analysis; 4 - level of sound pressure

Cleanliness of a surface after machining corresponded to 7 class. The deviation of the set sizes did not exceed $0,1 \mathrm{~mm}$. Acoustic properties defined after hot rolling, then the same samples subjected annealing or training. A mode annealing - having heated up to As $3+50{ }^{\circ} \mathrm{C}$, endurance 1 hour and cooling with the furnace. Training spent on mode of operation: having heated up to $\mathrm{Ac} 3+50^{\circ} \mathrm{C}$, endurance 0,5 hour, cooling in water or in oil. Heating of samples in muffle the laboratory furnace made in quartz ampoules in vacuum with relieve tension an order $10^{\circ} \mathrm{atm}$. (for prevention scale production).

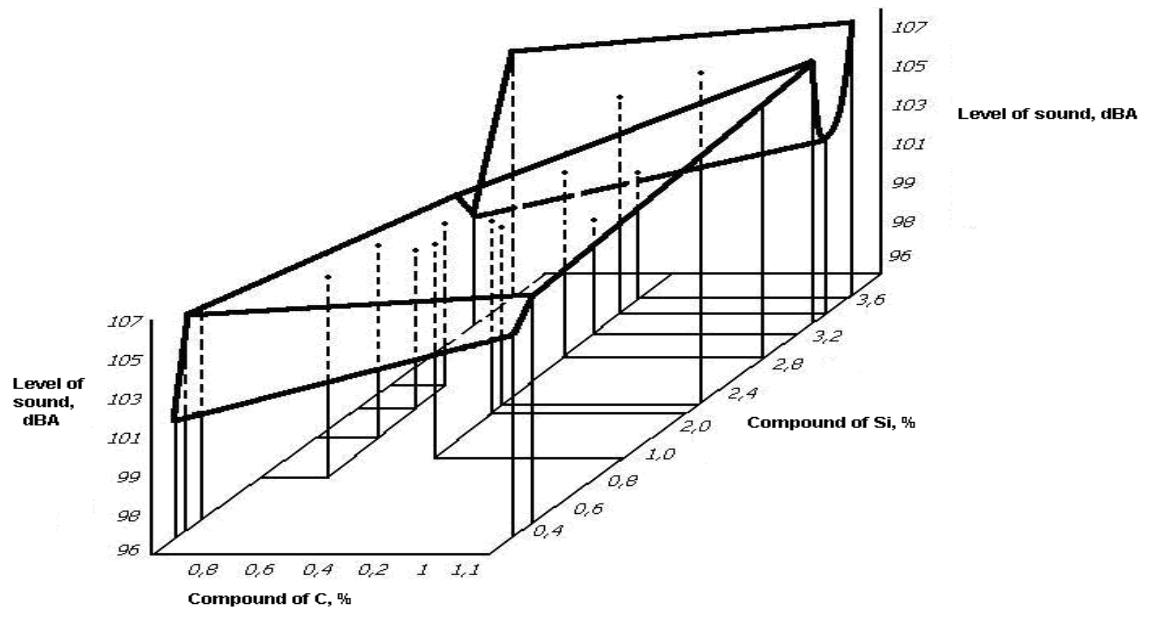

Figure - 2. Level of a sound of skilled steels in dependence from the carbon and silicon maintenance 


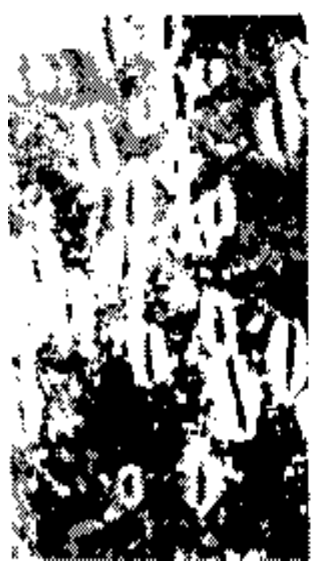

a

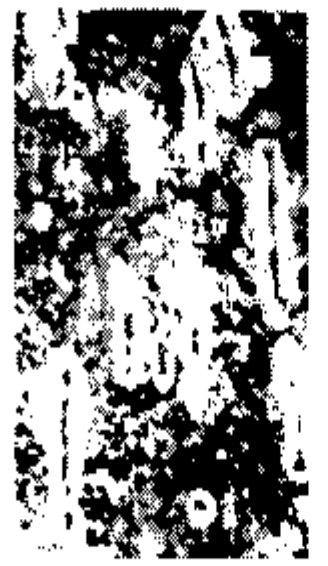

$\mathrm{b}$

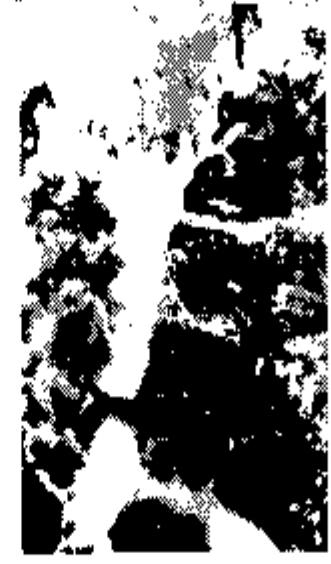

c

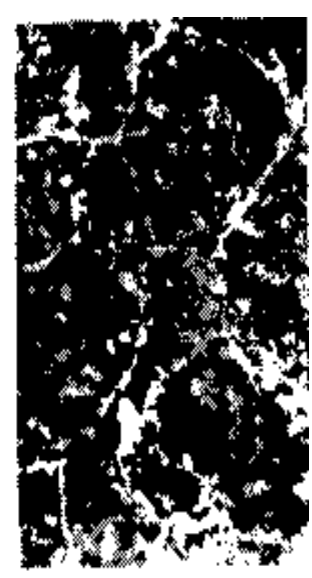

d

Figure - 3. Microstructure of steels after hot deformation (a), annealing (b and c) and double annealing (d) x 200

\begin{tabular}{|c|c|c|c|c|}
\hline \multicolumn{5}{|c|}{ Table I Chemical compound of steels, \%: } \\
\hline Steel & $\mathrm{C}$ & $\mathrm{Mn}$ & $\mathrm{Si}$ & $\mathrm{Ni}$ \\
\hline $\mathrm{a}$ & 1,01 & 0,22 & 3,09 & 1,43 \\
\hline $\mathrm{b}$ & 0,04 & 2,51 & 3,20 & 0,24 \\
\hline $\mathrm{c}$ & 0,45 & 1,52 & 1,53 & 0,40 \\
\hline $\mathrm{d}$ & 1,10 & 2,28 & 0,24 & 0,33 \\
\hline
\end{tabular}

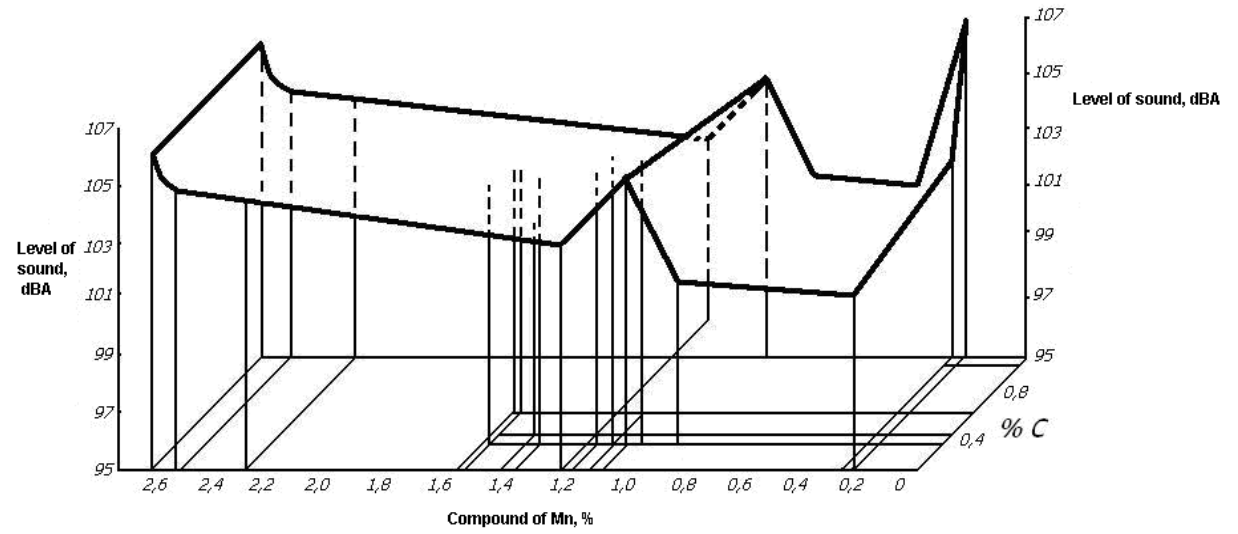

Figure - 4. Level of a sound of skilled steels in dependence from the carbon and manganese maintenance 
Influence of the maintenance of manganese within $0,2-2,6 \%$ on acoustic properties in alloys considerably is not shown that proves to be true the diagramme presented on Fig. 5. Though under the data [3,4] manganese and alloys on its basis possess high damping ability at small and at considerable amplitudes of deformation $(\varphi=7+40 \%)$, in alloys $\mathrm{Fe}-\mathrm{Mn}-\mathrm{C}$ damping ability is defined basically maintenance carbon and influence of manganese on phase transformations. Manganese, being dissolved in ferrite and incorporating to carbon with formation of carbides, raises hardness and durability of a steel. Because in the presence of transformation manganese move to lower temperature, and eutectoid it is formed at smaller concentration of carbon, the structure manganese steels is less differentiated. As manganese forms the carbides easily dissolved in austenite, investigated steels even at an insignificant overheat (900-950 $\mathrm{C}, 1$ hour the furnace) had large and rough grain both in to eutectoid, and in after eutectoid steels. However formation large coarsely grains has led to improvement damping to ability of a steel. Nickel, as well as manganese, forms with iron a firm solution of replacement, strengthen thus ferrite (Fig. 5). Nickel causes in a steel susceptibility to liquidation the heterogeneity caused by stratification of a homogeneous firm solution.
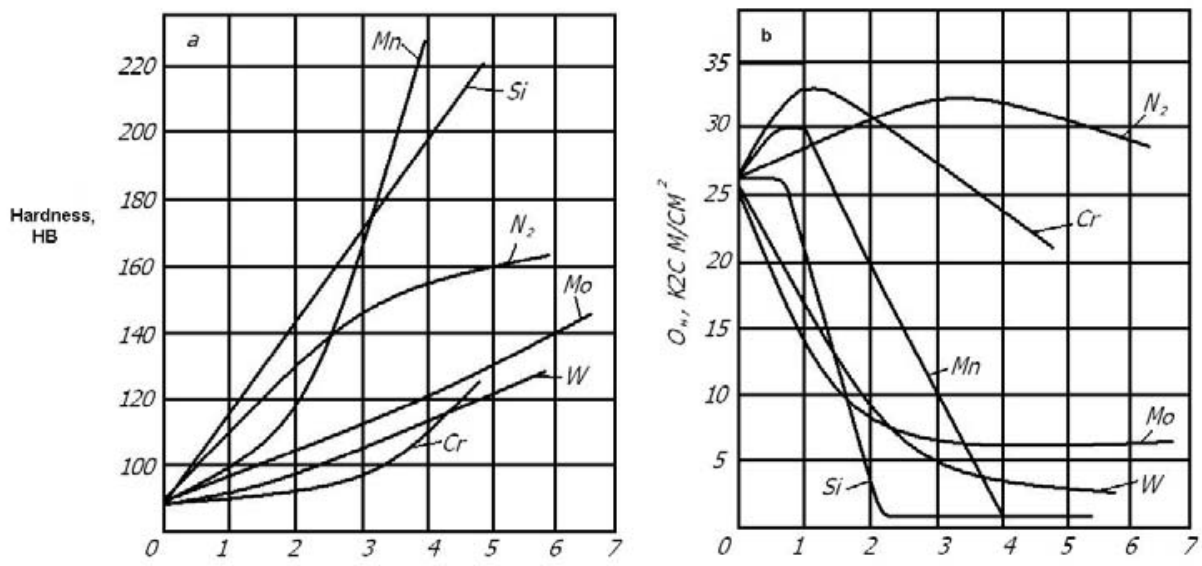

The maintenance of an alloying element, $\%$

Figure - 5. Influence of alloying elements on properties of ferrite 


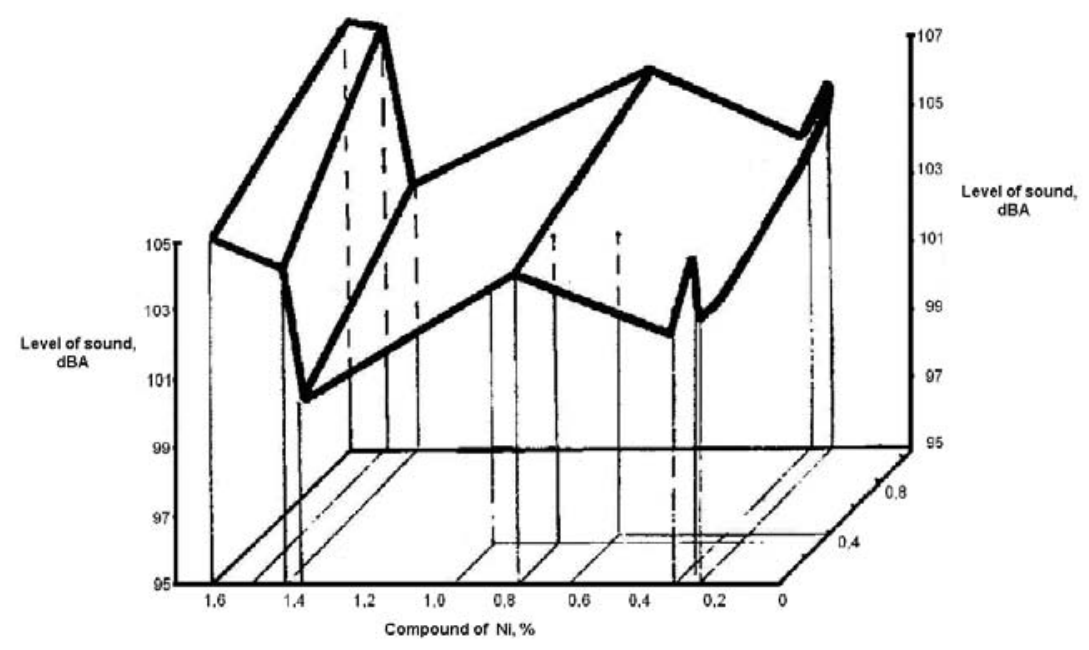

Figure - 6. Level of a sound of skilled steels in dependence from the carbon and nickel maintenance

Influence alloyed steels from 0.2 to $1.6 \%$ on acoustic characteristics is considerably shown by nickel at increase in its maintenance and at low carbon (an alloy 1). The diagramme (Fig. 6) shows that this alloy has the minimum value of level of a sound. Similar influence of the maintenance of nickel is found out and in an alloy 4 though the maintenance carbon in this alloy reaches $1,0 \%$, but apparently, from Fig. 4. Here goes, except that, process graphitization.

\section{CONCLUSION}

The conducted research of influence of a chemical compound of alloys on them damping properties has allowed to develop low alloyed the steels alloyed $\mathrm{Mn}, \mathrm{Si}$ and $\mathrm{Ni}$ with the lowered sound generation at shock excitation.

Application of a method of planning of experiment has allowed estimating the contribution of each alloying element in damping characteristics was development steels.

\section{REFERENCES}

[1] Suleyev D.K., Zhumadilova Zh.O., Utepov T.E. Application of a method of mathematical planning of experiment by development of alloys with advanced damping properties. Vestnik KazNTU named after K.I. Satpayev, 2008. №2 - p.24.

[2] Suleyev D.K. Research of microplastic deformation on a surface of the sample at impact with the drummer-sphere. Struggle against noise and sound vibration. The Collection of 
scientific publications of the International academy of sciences of ecology and safety of ability to live (IASES), 2001. p.31(Almaty).

[3] Alloy «KazNTU - IV» on an iron basis. Patent. №21005. 03.16.2009. KZ

[4] Zh.O. Zhumadilova. Influence of the chemical compound and heat treatment on damping properties of steels. Vestnik of Kazakh National Academic Science of the Republic of Kazakhstan. Almaty 2009, №4, July p.18. 